\title{
The Relation Between Anger Coping Strategies, Anger Mood and Somatic Complaints in Children and Adolescents
}

\author{
Anne C. Miers - Carolien Rieffe • \\ Mark Meerum Terwogt • Richard Cowan • \\ Wolfgang Linden
}

Published online: 7 June 2007

(C) Springer Science+Business Media, LLC 2007

\begin{abstract}
Attempts to explain the experience of somatic complaints among children and adolescents suggest that they may in part result from the influence of particular strategies for coping with anger on the longevity of negative emotions. To explore these relationships British $(n=393)$ and Dutch $(n=299)$ children completed a modified version of the Behavioral Anger Response Questionnaire (BARQ), and two additional questionnaires assessing anger mood and somatic complaints. A hierarchical regression analysis showed that for both the UK and Dutch samples two coping styles, Social support-seeking and Rumination, made a significant contribution to somatic complaints, over and above the variance explained by anger mood. A tendency to repeatedly think or talk about an angering event as a way of coping seems to underlie the observed negative health effects. In addition, tentative support is given for a broader range of strategies to cope with anger than just the traditionally studied anger-out and anger-in styles.
\end{abstract}

A. C. Miers $(\bowtie) \cdot$ C. Rieffe

Developmental Psychology, Leiden University,

PO Box 9555, 2300 RB Leiden, The Netherlands

e-mail: acmiers@fsw.leidenuniv.nl

M. Meerum Terwogt

Department of Developmental Psychology, Vrije Universiteit, Amsterdam, The Netherlands

R. Cowan

School of Psychology and Human Development,

Institute of Education, University of London,

London, UK

W. Linden

Psychology Department, The University of British Columbia,

Vancouver, Canada
Keywords Somatic complaints · Anger mood · Anger coping styles $\cdot$ Children $\cdot$ Adolescents

\section{Introduction}

The experience of physical complaints such as headaches, abdominal, limb and back pain is not unusual for children and adolescents. Epidemiological studies show that between 5 and $30 \%$ of eight to sixteen year-olds are afflicted by weekly headaches, recurrent abdominal pain (RAP) or musculoskeletal pain (Egger et al. 1999). These symptoms often occur in combination resulting in considerable pain for the individual (Perquin et al. 2000a, b; Taylor et al. 1996). However, seeking medical help does not always provide a solution. Indeed in a large number of cases, sometimes up to $90 \%$, an organic reason cannot adequately account for the frequent and persistent occurrence of somatic symptoms (Compas and Harding Thomsen 1999; Croffie et al. 2000; Edwards et al. 1994; Roth-Isigkeit et al. 2004). The absence of a clearly detectable organic cause has prompted researchers to investigate the role of psychological factors, notably those in the emotional domain (Jellesma et al. 2006; Rieffe et al. 2006).

The idea that emotions have the potential to adversely impact upon the mind and body dates back to the GrecoRoman era when prominent physicians and philosophers e.g., Aristotle, linked illness with emotion (Taylor 1997). Although depression and anxiety are widely studied as emotional components of pain, anger has been identified as one of its most 'salient' properties (Fernandez and Turk 1995). This is borne out in studies of adults with chronic illnesses or persistent pain who either report feeling angry (Zimmerman et al. 1996) or who are observed exhibiting angry feelings (Kerns et al. 1994; Moldofsky and Chester 1970). Indeed, in 
a recent review of the literature it was concluded that supporting evidence for a link between high anger levels and pain continues to build (Greenwood et al. 2003).

\section{Anger Coping and Health: The Dichotomous Approach}

In attempting to explain how an enduring angry affect may arise and produce internal bodily changes many studies have focused upon the influence of 'extreme' anger expression styles. The suggestion is that individuals who either suppress feelings of anger or direct it inwards, known as anger-in, or display their anger in an overtly aggressive manner, termed anger-out, are most at risk of harming the body. These two anger expression styles are typically measured using Spielberger's questionnaire, the Spielberger Anger Expression Scale (SAES; Spielberger et al. 1985) which assesses how an individual responds to the experience of feeling angry. This questionnaire has been referred to as a measure of anger coping styles (e.g., Eng et al. 2003; Linden et al. 2003). Taking the definition of coping as a means of regulating emotional arousal (Losoya et al. 1998) it can be argued that these expression styles reflect ways of coping with anger, as either aggressively venting one's anger or deliberately keeping the anger inside are likely to modify one's anger arousal level.

Empirical support for the influence of these anger coping styles on cardiovascular health is well documented in the adult literature. For example, some studies have found significant positive relationships between anger-in and increases in blood pressure, and an increased risk of hypertension (e.g., Gentry et al. 1982). High levels of anger-in have also been related to coronary heart disease (Gallacher et al. 1999). Other research reports associations between anger-out and two health risks; heart rate reactivity (Siegman et al. 1992; Suarez and Williams 1990) and hypertension (Harburg et al. 1991).

The relationship between anger coping styles and other less hard health indices, such as somatic complaints, has also been examined (Martin et al. 1999). High levels of anger-out were associated with an increased number of selfreported physical symptoms in an adult sample, whereas both anger-out and anger-in correlated positively with frequency of physical complaints in a sample of college students (Martin et al. 1999).

\section{Anger Coping and Health: A Multidimensional Approach}

Although the vast majority of the anger-health literature is dominated by the dichotomous approach to anger coping styles, a number of independent research groups have demonstrated that anger is more likely to be a multidimensional construct than a simple split between anger-in and anger-out (Friedman et al. 1995; Miller et al. 1995; Riley and Treiber 1989). In addition, it is claimed that a broader approach to anger, including both behavioral and cognitive coping strategies, could potentially provide a better explanation of the anger-health connection (Linden et al. 2003).

To address these issues Linden et al. (2003) developed a new measure of anger-the 'Behavioral Anger Response Questionnaire (BARQ)'-with the aim of capturing a more comprehensive view of anger coping. Two of the six BARQ coping strategies, Direct Anger-out and Avoidance, are similar to the anger-out/anger-in strategies in that they represent 'extreme' strategies of aggression on the one hand and passivity/suppression on the other. In addition, three moderate or adaptive response styles are included; Assertion refers to the ability to constructively express one's anger or solve the angering event, Diffusion involves deflecting the anger to another stimulus or activity, and Social support-seeking describes finding support from a friend or relative. The sixth BARQ strategy, Rumination, taps the tendency to cope with one's anger by repeatedly deliberating over its cause (Linden et al. 2003).

Meaningful relationships between the use of BARQ coping styles and health outcomes have been established in two studies among adults. Reductions in blood pressure among hypertensive patients were associated with an increase in Social support-seeking and a decrease in Direct Anger-out (Linden et al. 2001). Hogan and Linden (2004) showed that women's blood pressure levels benefited from using Assertion but worsened with an Avoidance expression style. In the same study, Rumination was found to interact with other coping styles in its effects on cardiovascular outcomes. Assertion's advantageous effect on women's blood pressure was cancelled out by use of Rumination and, for male participants the consequences of Avoidance were aggravated (Hogan and Linden 2004).

\section{Anger and coping from a Developmental Perspective}

It is widely acknowledged that anger is socially perceived as "maladaptive" to social relationships in Asian, collectivistic cultures (Markus and Kitayama 1991). Yet, within the Western, individualistic culture, anger expression is not promoted either. For example, we see that mothers pay less attention to their angry toddlers; they mostly ignore them, whereas the expression of sadness or fear more often evokes immediate maternal support (Buss and Kiel 2004). Most studies on anger have concentrated on aggression (e.g., Lemerise and Dodge 1993) or hiding one's anger (e.g., Underwood 1997), and only few studies have examined the 
adaptive function of anger expression (e.g., Rieffe and Meerum Terwogt 2006), despite the fact that anger occurs more often without aggression (DiGiuseppe et al. 1994; Averill 1982). Due to this common sense idea that anger expression should be discouraged, managing anger in a competent manner might be difficult. In line with this, the finding that the expression of anger towards peers increases with age (Underwood 1997; Underwood et al. 1992) and that adolescents use negotiation more frequently than children to cope with anger (von Salisch and Vogelgesang 2005), suggest that older and thus presumably more emotionally competent children find it easier to manage their anger.

Young children frequently use distraction as a coping strategy for different types of events. Many six year olds will engage in some kind of pleasant activity, such as watching a video or playing a game. It is not before their tenth year that children start to appreciate the role of more complex cognitive processes, such as re-evaluating the situation, e.g., "It is not that bad, I didn't care about that toy anyway." However, ten year old children do not switch from behavioural to cognitive strategies; instead they use them complementarily and if possible, a behavioural approach is usually tried initially, even in adults (for an overview, see Fields and Prinz 1997). Thus, from this age children have a wider range of coping strategies available to apply to different situations, including angering events (von Salisch and Vogelgesang 2005).

\section{Anger coping and Health: Empirical Evidence from Child studies}

The use of coping strategies related to medical procedures and pain complaints in children has frequently been investigated (e.g., Last and Grootenhuis 1998), but studies concerning coping strategies in relation to stressful events in children with more somatic complaints are scarce. Preliminary outcomes seem to show that children or adolescents with more pain or other somatic complaints use fewer or less effective coping strategies to deal with their negative emotions (Bonner and Finney 1996; Rector and Roger 1996; Sharrer and Ryan-Wenger 1991; Walker et al. 2001). Furthermore, in comparison with the adult literature, scant attention has been paid to the relationship between anger coping styles and health in children and adolescents. Instead, research has mainly focused on the link between somatic complaints, anxiety and depression (Bandell-Hoekstra et al. 2000; Campo et al. 2004; Egger et al. 1999). One study which did examine the link between anger and health among a group of adolescents found that whilst the coping styles anger-out and anger-in had a negative association with current health, the experience of somatic symptoms was not significantly correlated with any anger coping variable (Yarcheski et al. 2002).

Children's health has also been linked directly to anger mood. In contrast to an emotion, mood is a long lasting affective state which cannot be attributed to a specific causal event (Scherer 2000). Two studies have shown that children who report many physical complaints also report higher levels of anger mood than their well peers (Jellesma et al. 2006; Rieffe et al. 2004). It is assumed within the adult literature that certain coping styles influence health through their effects on the longevity of negative emotion. Continuously elevated anger levels are thought to place an unnecessary demand on the physiological system, which in turn then becomes more susceptible to detrimental health effects (Martin et al. 1999). It is important, therefore, to consider how children and adolescents' style of coping with anger may impact upon their mood and, in turn, their experience of somatic complaints.

\section{The Present Study}

The purpose of the present study was to examine the relationships between ways of coping with the emotion anger, anger mood and somatic complaints in a child and adolescent population. More specifically, associations between coping strategies and anger mood were first tested, and secondly the contribution of anger coping strategies to somatic complaints over and above anger mood was explored. These relationships were tested in two samples of children and adolescents from two Northern European countries, the UK and the Netherlands. A new, modified version of the BARQ (Linden et al. 2003) was used to measure anger coping styles. Based on findings from Linden et al. using the adult BARQ it was expected that Direct Anger-out, Avoidance and Rumination would be significantly related to higher levels of anger mood whereas the so-called adaptive styles (Assertion, Social-support seeking and Diffusion) were hypothesized to be significantly related to less anger mood (Hogan and Linden 2004; Linden et al. 2001; Linden et al. 2003). Consistent with prior research, anger mood was hypothesized to be positively related to somatic complaints (Jellesma et al. 2006; Rieffe et al. 2004). Given the exploratory nature and the absence of previous, direct evidence on which to base predictions, no specific hypotheses were formulated with respect to anger coping styles and somatic complaints.

Information on these three key constructs, anger coping styles, anger mood and somatic complaints, was collected from participants themselves using self-report questionnaires. Self-report is thought to be a particularly accurate 
way of measuring emotion because participants have direct knowledge about their own emotions. It is therefore more advantageous to ask the respondent rather than use another source of information (Baldwin 2000 as cited in Larsen and Prizmic 2006; Feldman-Barrett 2004). It has been suggested that children are the most important source of information in relation to internalizing symptoms, such as somatic complaints (Achenbach et al. 1987) and that as children get older they become increasingly reliable reporters of such symptoms (Mellor 2004). Furthermore, children are better at predicting their own anxiety than are either parents or teachers (DiBartolo and Grills 2006). Quite a significant body of work, then, exists to bolster the use of self-report methods when investigating constructs such as emotions and internalizing symptoms.

As a final point, note that whether or not an organic cause for physical complaints can be identified does not seem to affect the strong associations found between psychological functioning and pain complaints. Various studies comparing children with medically unexplained symptoms and children for whom an organic problem had been diagnosed show no differences between the two groups in terms of their psychological functioning (Jellesma et al. 2006; Nygaard et al. 2004; Walker et al. 1993). Therefore, we chose to examine the suggested anger copinganger mood-somatisation relationships in a normal population, without consideration of participants' medical history, but based on children and adolescents' self-reported somatic complaints.

\section{Materials and Methods}

\section{Participants}

A total of 692 children and adolescents from two separate samples took part in this study. Participants from the UK and the Netherlands were recruited in the same manner, namely by contacting schools located in or close to major cities in each country and obtaining permission from the school to collect information from school pupils. Participants from the UK attended one of three different urban secondary schools and in the Netherlands participants were drawn from one primary and one secondary school situated in the Randstad, the most industrialized part of the Netherlands. The samples are comparable with respect to social class, each reflecting an average social economic status level. The UK sample consisted of 393 participants, including 196 boys and 197 girls, with a mean age of 13.6 years (age range $11.1-16.3$ years, $S D=1.23$ years). The Dutch sample contained 299 children and adolescents, including 151 girls and 148 boys, with a mean age of 11.7 years (age range 9.7-14.2 years, $S D=1.02$ years).
Materials

\section{The Behavioral Anger Response Questionnaire (BARQ)}

To measure anger coping styles in children and adolescents the Behavioral Anger Response Questionnaire for adults (Linden et al. 2003) was adapted, with permission from Linden, by a team of developmental psychologists. The revised version is termed BARQ-C, to indicate its use for children and adolescents. The original BARQ has demonstrated good internal consistency (mean $\alpha=0.76$, range $0.65-0.85$ ) and acceptable construct validity (Linden et al. 2003). The adapted English and Dutch versions of the BARQ-C ask children and adolescents to rate a total of 37 items, on a Likert scale, stating the degree to which each item is true about them when feeling angry $(1=$ not true, $2=$ sometimes true, $3=$ often true).

The adult version was first adapted for English speaking children and adolescents. This involved simplifying the language of its items, for example common phrases used to describe the source of the anger such as 'the angering person' and 'the angering event' were changed to 'the person who angered me' and 'what happened,' respectively. Items worded with a particular adult theme were also modified to make the items more relevant to children, e.g., 'I raise my voice' was changed to 'I shout' and 'I work off my frustration by cleaning the house, organizing the office, or by doing garden work' was modified to 'I work off my anger by doing something else, like playing on the computer.' The adapted version was checked by school teachers and was deemed to have a reading level appropriate for children aged 9 years and above.

The English version for children and adolescents was translated into Dutch by partly the same team of developmental psychologists who adapted the English version for a non adult population. The first version of the Dutch questionnaire was sent to a participating primary school where a group of teachers checked the wording of the items for suitability and relevance to the selected age group. Any discrepancies were discussed and suggestions for improvements sent back to the team. The questionnaire was then revised according to the suggestions and sent back to the school for final approval.

\section{The Mood list for children (De Stemmingslijst voor kinderen)}

The Mood list was previously developed in parallel for use among English speaking and Dutch speaking children and adolescents (Rieffe et al. 2006). It consists of 20 items that describe four different moods: Happiness, Anger, Sadness and Fear. Participants are required to rate on a 3-point scale (never/ sometimes/often) how they have been feeling lately. 
For this study only items from the anger scale were used, which are: mad, angry, cross and furious. The internal consistency of the anger mood scale has been established in previous work ( $\alpha=0.77$, Rieffe et al. 2006). In the present study the internal consistency reached 0.75 in the UK sample and 0.74 in the Dutch.

\section{The Somatic Complaint List (SCL; Somatiek Index)}

The Somatic Complaint List (Rieffe et al. 2006) was developed with the aim of providing a short, reliable measure of how often children and adolescents experience and feel pain. Dutch and English versions were previously

Table 1 Items from the UK BARQ-C and factor loadings from the first half of each sample

Item wording

Direct Anger-out

In an angry way I tell the person who made me angry exactly how I feel

I say something nasty to the person who made me angry

I use strong gestures (for example, make a fist, wave my arms, or give a hand sign)

I swear, or curse at the person who made me angry

I hit or push the person who made me angry

I express my anger by slamming a door, or hitting something

I shout

Assertion

I wait until I am calm again and then talk to the person who made me angry

I carefully think it over and then tell the person who made me angry how I feel

In a In a calm voice, I tell the person who made me angry how I honestly feel

I try to understand what happened, so I can explain things to the person who made me angry

I stay calm, and I try to talk about the problem with the person who made me angry

I leave the situation in order to calm down, and then try to solve the problem

Social support-seeking

I do not show my anger but I talk about what happened with someone afterwards

I leave the situation and look for someone who will agree with me

I leave the situation, find someone to listen to my story, and ask for advice

I think about the problem first and then talk about it with someone

I leave the situation and call a friend or family member to tell him/her how I feel

Even without planning it, I usually end up talking about my feelings with someone

Diffusion

I get rid of my anger by playing music, writing, or painting

I just keep busy, until I stop feeling angry

I work off my anger by doing some sport

I stay on my own to get rid of my anger

I simply get very busy with other things to get rid of my anger

I work off my anger by doing something else, like playing on the computer

Avoidance

I tell myself that what happened is not important.

I try to forget what happened

I put what happened out of my mind

I do not want to have to cause trouble, so I keep my feelings to myself

I just wait to feel better

I try to keep busy so I can forget about what happened

Rumination

I try to understand why I got upset

I imagine how I could get even with the person who made me angry

I keep thinking about what I wish I had done, but didn't do

I find it hard to stop thinking about what happened

I am upset for a long time after this kind of situation

In my mind, I go over the situation that made me angry again and again

Factor Loading $\mathrm{UK}^{\mathrm{a}} / \mathrm{NL}^{\mathrm{b}}$

.$-1 .-$

$0.64 / 0.71$

$0.60 / 0.74$

$0.65 / 0.79$

$0.69 / 0.79$

$0.58 / 0.41$

$0.68 / 0.39$

$0.37 / 0.51$

$0.64 / 0.75$

$0.66 / 0.64$

$0.74 / 0.72$

$0.72 / 0.64$

$0.40 / 0.37$

.-/0.58

.-/0.63

.-/0.64

.- -0.56

.- -0.55

.-/0.63

.- -0.66

$0.54 / 0.63$

$0.53 / .-$

$--/ 0.52$

$0.71 / 0.59$

$0.66 / 0.55$

$0.56 / 0.65$

$0.32 / 0.64$

$0.38 / 0.36$

.- .-

.- - -

.$-/ 0.31$

.- - -

.---

$0.47 / 0.65$

$0.70 / 0.65$

$0.70 / 0.56$

$0.67 / 0.64$

Note Factor loadings below .30 are indicated with a dash (.-). Items in Italics were removed from the corresponding scale. $B A R Q-C=$ Behavioral Anger Response Questionnaire for children and adolescents.

${ }^{\mathrm{a}} n=197,{ }^{\mathrm{b}} n=150$. 
constructed in parallel (Rieffe et al. 2006). Items on the SCL are based on observations of school teachers and reflect more common complaints experienced by children and adolescents (e.g., 'feeling tired') than some of the items on the Children's Somatisation Index (CSI; Walker and Greene 1989) such as 'numbness or tingling' (Jellesma et al. in press). Consisting of 11 items the SCL covers both pain related symptoms (e.g., 'headache' and 'stomach ache') and broader somatic symptoms (e.g., 'dizzy' and 'nauseous'). Participants are required to rate each item on a 3 -point Likert scale $(1=$ never, $2=$ sometimes, $3=$ often $)$ according to the frequency with which they experience that complaint or symptom. Two of the items are positively formulated and are thus reverse scored. This questionnaire has repeatedly demonstrated good reliability $(\alpha>0.75$, Jellesma et al. 2006; Meerum Terwogt et al. 2006; Rieffe et al. 2006) and is stable over a half year period (Jellesma et al. in press). In this study, the reliability of the SCL reached an adequate level in both the UK $(\alpha=0.82)$ and Dutch $(\alpha=$ 0.75) samples.

\section{Procedure}

Prior to conducting the study, permission to participate was obtained from parents in the UK and the Netherlands. The selected questionnaires were administered in school classrooms to UK and Dutch participants. Additional questionnaires that were not utilized for the present study were also distributed. Before completing the questionnaires the aims of the study were explained, highlighting that participation was voluntary and anonymous. It took approximately 25 min for participants to complete the selected questionnaires. They were completed in the following, fixed order: BARQ-C, Mood list and SCL. Once finished, the participants were thanked for their time and any questions addressed.

\section{Results}

Psychometric properties of the BARQ-C

Before testing the proposed relationships between anger coping styles, anger mood and somatic complaints the psychometric properties of the BARQ-C were examined in each sample. In order to cancel out chance effects associated with any one given sample a cross validation method was used. Firstly, items were selected on the basis of factor analysis and internal consistency results in one half of each sample (randomly selected) and secondly, the new factor structure was tested in the remaining half of each sample. British and Dutch children's responses from the first half of each sample were entered into a principal components analysis (PCA) with varimax rotation. ${ }^{1}$ In keeping with the original theory a six-factor structure was specified (Direct Anger-out, Assertion, Social supportseeking, Diffusion, Avoidance and Rumination; Linden et al. 2003). Eigenvalues ranged between 1.3 and 6.1 in the UK first half sample and between 1.5 and 5.5 in the Dutch first half sample. The 6 factor solution explained 45.7 and $47.7 \%$ of the variance in the selected UK and Dutch samples respectively. Items from the UK version and the corresponding factor loadings for both first half samples are presented in Table 1. It can be seen that the majority of items had factor loadings above 0.40 . In both samples items from Assertion and Direct Anger-out loaded highly on the intended factors, apart from one Direct Anger-out item. This was also true of Social support-seeking in the Dutch sample. In the UK data, items from Social support-seeking did not cluster on a separate factor. The same pattern in each sample emerged for Rumination whereby a group of four items loaded highly on the keyed factor. Not all items from Avoidance and Diffusion subscales loaded on the intended factor, with three items from each subscale showing overlap between the two samples.

An attempt was then made to improve the factor structure of the BARQ-C. In line with the PCA, removal of one Direct Anger-out and two Rumination items, which did not load on the intended factor, increased the internal consistency for both first half samples (Direct Anger-out: from 0.76 to 0.78 and 0.75 to 0.80 ; Rumination: from 0.59 to 0.71 and 0.65 to 0.72 , in UK and Dutch half samples respectively). However, omitting weak items highlighted by the PCA from the Avoidance and Diffusion subscales did not improve the internal consistency in either half sample. These two subscales were thus left intact.

The final BARQ-C subscales are presented in Table 2 with the number of items and, where appropriate, adjusted internal consistency. Direct Anger-out, Assertion and Rumination show good internal consistency in both first half samples. Diffusion and Avoidance do not reach adequate internal consistency and items from Social Support-seeking, whilst failing to cluster together, do show a reasonable degree of internal consistency in the UK sample, and a satisfactory internal consistency in the Dutch sample.

Next, the factor structure of the modified BARQ-C (6 factors, 34 items) was tested in the remaining second half of

\footnotetext{
${ }^{1}$ The data were also subject to a PCA using an oblique rotation method. The component correlation matrix showed low correlations between the six factors suggesting that it was more appropriate not to allow the factors to intercorrelate (Pedhazur and Schmelkin 1991; Tabachnick and Fidell 2007).
} 
Table 2 Internal consistency (Cronbach's alpha) of the BARQ-C subscales by first and (second) half of each sample

\begin{tabular}{|c|c|c|c|c|c|}
\hline \multirow[t]{2}{*}{ Questionnaire } & \multirow[t]{2}{*}{ No. of items } & \multicolumn{2}{|l|}{ UK } & \multicolumn{2}{|l|}{ NL } \\
\hline & & Cronbach's alpha & Inter-item correlation & Cronbach's alpha & Inter-item correlation \\
\hline \multicolumn{6}{|l|}{ BARQ-C corrected scales } \\
\hline Direct Anger-out & 6 & $0.78(0.81)$ & $0.38(0.41)$ & $0.80(0.80)$ & $0.40(0.41)$ \\
\hline Assertion & 6 & $0.76(0.77)$ & $0.34(0.36)$ & $0.77(0.81)$ & $0.35(0.41)$ \\
\hline Social support-seeking & 6 & $0.65(0.71)$ & $0.23(0.29)$ & $0.74(0.73)$ & $0.32(0.31)$ \\
\hline Diffusion & 6 & $0.54(0.62)$ & $0.17(0.22)$ & $0.61(0.62)$ & $0.21(0.22)$ \\
\hline Avoidance & 6 & $0.60(0.65)$ & $0.20(0.23)$ & $0.55(0.59)$ & $0.16(0.20)$ \\
\hline Rumination & 4 & $0.71(0.73)$ & $0.37(0.40)$ & $0.72(0.75)$ & $0.38(0.43)$ \\
\hline
\end{tabular}

Note BARQ-C $=$ Behavioral Anger Response Questionnaire for children and adolescents. Internal consistencies from the second half of each sample are shown in brackets. First half sample: UK $n=197$, NL $n=150$. Second half sample: UK $n=196$, NL $n=149$.

each sample. This resulted in 50.54 and $51.20 \%$ explained variance in the UK and Dutch second half samples respectively. The reliability coefficients of each subscale for the second half of each sample are also shown in Table 2. It can be seen that all subscales either maintained satisfactory internal consistency or showed an improvement (e.g., Social support-seeking). Avoidance and Diffusion remained below the required alpha level of 0.70 .

The similar results from this cross validation procedure attest to the robustness of the derived factor structure in both samples and is therefore applied in subsequent analyses. The anger coping, anger mood and somatic complaints relationships are, as a consequence, examined using data collapsed across the UK and Dutch samples, increasing power and controlling for age. ${ }^{2}$ Descriptive statistics for all variables are presented in Table 3.

\section{Anger Coping Styles, Anger Mood and Somatic} Complaints

Pearson correlations were first calculated between anger mood and the six BARQ-C coping styles. ${ }^{3}$ Direct Angerout was significantly positively associated with angry mood $(r=0.43, p<0.01)$. Whilst this is in line with expectations the opposite maladaptive style, Avoidance, did not show the same relationship. Greater use of the Avoidance coping style was associated with significantly lower levels of anger $\operatorname{mood}(r=-0.19, p<0.01)$. As hypothesized Rumination was associated with higher levels of anger mood $(r=0.14$,

\footnotetext{
$\overline{2}$ The hierarchical regression analysis was also performed for each land separately. This yielded the same results and thus supports collapsing data across the two samples.

${ }^{3}$ Partial correlations controlling for the effect of Age showed the same relationships between anger coping styles and anger mood. Age was not a significant predictor of somatic complaints in the hierarchical regression analysis either. This variable was therefore removed from the text and tables.
}

$p<0.01$ ), whereas greater use of Assertion was significantly correlated with less angry mood $(r=-0.14, p<0.01)$. Social support-seeking and Diffusion did not correlate significantly with anger mood. These correlations were conducted for boys and girls separately; no gender differences were found in the pattern described here.

The next stage was to test which anger coping styles independently influence the presence of somatic complaints over and above that of anger mood. Firstly, the expected positive relationship between anger mood and somatic complaints was supported $(r=0.28, p<0.01)$. Secondly, a hierarchical regression analysis was conducted with somatic complaints as the criterion variable, in which anger mood was entered in the first step and the six BARQ-C subscales in the second step. Correlations between independent variables did not invalidate the multicollinearity assumption; correlations ranged between -0.04 and 0.50 , the latter between Social support-seeking and Assertion (Tabachnick and Fidell 2007). Standardized regression coefficients were used for interpretation. Table 4 shows the results of this analysis. As expected higher levels of anger mood significantly predicted increased levels of somatic complaints.

Table 3 Means and standard deviations of somatic complaints list, anger mood subscale and BARQ-C subscales $(N=692)$

\begin{tabular}{lcc}
\hline Subscale & Mean & SD \\
\hline SCL & 1.71 & 0.35 \\
Anger mood scale & 1.83 & 0.41 \\
BARQ-C corrected subscales & & \\
Direct Anger-out & 1.90 & 0.52 \\
Assertion & 1.76 & 0.45 \\
Social support-seeking & 1.84 & 0.45 \\
Diffusion & 1.99 & 0.44 \\
Avoidance & 1.98 & 0.40 \\
Rumination & 1.95 & 0.53 \\
\hline
\end{tabular}

Note BARQ-C = Behavioral Anger Response Questionnaire for children and adolescents. SCL Somatic Complaints List (Rieffe et al. 2006). 
Table 4 Summary of hierarchical regression analysis for anger mood and anger coping styles on somatic complaints $(N=692)$

\begin{tabular}{llll}
\hline Variable & B & SEB & $\beta$ \\
\hline $\begin{array}{l}\text { Step 1: } \\
\quad \text { Anger Mood }\end{array}$ & 0.25 & 0.03 & $0.28^{*}$ \\
Step 2: & & & \\
$\quad$ Anger Mood & 0.22 & 0.03 & $0.25^{*}$ \\
BARQ-C subscales & & & \\
Assertion & 0.00 & 0.03 & 0.00 \\
Direct Anger-out & 0.01 & 0.03 & 0.01 \\
Social support-seeking & 0.11 & 0.04 & $0.14^{*}$ \\
Rumination & 0.11 & 0.03 & $0.16^{*}$ \\
Avoidance & -0.00 & 0.03 & -0.00 \\
Diffusion & -0.04 & 0.04 & -0.04 \\
\hline
\end{tabular}

Note $R_{\text {adj }}^{2}=0.08$ for Step $1 \quad(p<0.001) ; \Delta R^{2}=0.06$ for Step 2 $(p<0.001)$. BARQ-C $=$ Behavioral Anger Response Questionnaire for children and adolescents.

$* p<0.01$

With the addition of the anger coping scales a significant increase in the amount of explained variance occurred. Whilst anger mood maintained its positive contribution to somatic complaints in the second step, two anger coping styles also explained variance in somatic complaints. Greater levels of Social support-seeking behavior and Rumination predicted more somatic complaints. No other coping styles significantly contributed to somatic complaints in the presence of anger mood.

\section{Discussion}

The aim of this article was to investigate the role of anger in relation to the experience of frequent and co-occurring somatic complaints by children and adolescents. First, strategies to cope with an angering event were studied in terms of their relationship with anger mood and, secondly, the ability of these coping strategies to explain the variance in somatic complaints, over and above anger mood, was tested. A new instrument, The Behavioral Anger Response Questionnaire (BARQ; Linden et al. 2003), was employed as the measure of coping with an angering event. The relationships between anger coping strategies and anger mood will first be discussed, followed by findings regarding the explanation of somatic complaints through anger mood and anger coping styles. The factor structure and psychometric properties of the BARQ in a child and adolescent sample will also be considered.

\section{Anger Coping Styles and Anger Mood}

In line with hypotheses, anger mood was found to be positively related to a Ruminative coping style and the use of Direct Anger-out type strategies e.g., hitting something or shouting. Consistent with predictions Assertion correlated negatively with anger mood. Avoidance also showed a negative relationship with anger mood, but this finding is in opposition to expectations. The remaining two BARQ-C strategies, Social support-seeking and Diffusion did not show a significant relationship with self-reported anger mood.

The positive association between Direct Anger-out and anger mood is consistent with the work of Bushman (2002), who showed that thinking about the person who angered you whilst engaging in prototypical anger-out behavior, hitting a punching bag, significantly increases anger mood levels compared to doing nothing or thinking about getting fit at the same time as hitting the punching bag. The finding that greater use of Rumination to cope with an angering event is related to higher anger mood levels coincides with previous work on the relation between rumination and mood disturbances (Watkins 2004).

It is interesting to note that greater use of Avoidance was linked to lower anger mood levels. Apparently, the more a participant actively tried to ignore the problem, reduce its importance and keep feelings hidden, the less strong their anger mood. This outcome is similar to Bushman's (2002) finding that participants who were instructed to distract themselves from the angering person reported similar levels of anger mood as those who just had to sit quietly. This result does, however, counter the suggestion that Avoidance, like anger-in, is a maladaptive coping strategy. Comparing the two constructs, anger-in and Avoidance, it becomes evident that the items from each subscale do not wholly overlap. For example, the anger-in subscale of Spielberger et al. (1985) contains items like "I tend to harbor grudges I don't tell anyone about," "I keep things in" and "I boil inside but I don't show it." These items clearly differ to the majority of the items from the Avoidance scale, which focus more on forgetting about the angering incident. Only one item from this scale can be said to directly reflect the anger-in concept of suppressing feelings; "I do not want to have to cause trouble, so I keep my feelings to myself." Thus, as the name of the subscale suggests, Avoidance is more about mentally trying to avoid dealing with the problem. Whilst there is quite a body of evidence which points to the fruitlessness of this type of coping strategy in response to stress (Connor-Smith et al. 2000) it cannot be ruled out that actively trying to forget about the situation may actually be adaptive and related to lower anger mood level.

Anger Coping Styles, Anger Mood and Somatic Complaints

In line with expectations and previous research (Jellesma et al. 2006; Rieffe et al. 2004) anger mood was significantly associated with higher levels of self-reported somatic 
complaints. As children and adolescents' level of anger mood increased so did the frequency with which they experienced negative physical symptoms. When looking at the results of the hierarchical regression analysis anger mood clearly maintained its positive relationship with somatic complaints in the presence of the BARQ-C coping styles. However, it was not the only variable to make a significant contribution to the explanation of somatic complaints. Social support-seeking and Rumination were found to be positively related to the level of somatic complaints in British and Dutch children, over and above the contribution of anger mood. Thus, independent of whether anger mood increases or decreases, the more one seeks support/advice from other people or consistently thinks about the angering event, the greater the number of physical complaints reported. The remaining coping styles (Direct Anger-out, Assertion, Avoidance and Diffusion) did not directly contribute to somatic complaints.

That Rumination had a positive relationship with somatic complaints concurs with previous evidence in which the negative effects of repeatedly thinking about the angering person or event are documented (Hogan and Linden 2004). Given that Social support-seeking has been shown to have a positive influence on the occurrence of physical complaints (Linden et al. 2001) the present finding in relation to this coping strategy is perhaps unexpected. However, it must be noted that Linden et al. studied a population of hypertensive adult patients and measured the effects on a very different health parameter; blood pressure. It is thus difficult to make a direct comparison between this and the present study. Moreover, according to Kuppens et al. (2004) the function of social support seeking is merely to reaffirm one's views about the angering person or event as opposed to using advice from others to change one's perspective. In this vein, Social support-seeking may only serve to prolong one's angry mood rather than help reduce it, as indicated by the non-significant correlation between these two variables. Furthermore, Kuppens et al. (2004) demonstrated a link between social sharing and anger-in, the latter of which has demonstrable negative health consequences (as described earlier).

Taking Rumination and Social support-seeking together, what seems to be common to both is the implication of a sense of repetition or frequently going over the angering event, either with other people or in one's own mind, which is absent among the other anger coping strategies. These strategies imply a degree of preoccupation with the angering person and/or event without actually reaching a solution. It is possible that such preoccupation may contribute to the continuation of one's existing anger mood level and that this prolongation leads to negative changes in bodily functioning. This assumption does, of course, need to be empirically tested in future research.
Psychometric Properties of the Behavioral Anger Response Questionnaire for children

The theoretical structure of the BARQ assessing six strategies (Direct Anger-out, Assertion, Social supportseeking, Diffusion, Avoidance and Rumination) was first examined in half of each sample and the revised structure then cross validated in the second half of each sample. Overall, satisfactory support was shown for this structure in the Dutch and British samples. Three anger coping scales showed good psychometric properties in both samples: Assertion, Direct Anger-out, and Social support-seeking. Thus, although the latter scale's items did not cluster together in the UK sample - which was the only notable difference between the two samples - they do correspond with one another in a meaningful way. As supported by the factor analysis, Rumination too displayed good internal consistency after two items were omitted from the English and Dutch BARQ-C. Diffusion and Avoidance sustained unacceptable Cronbach's alphas and could not be improved by removing weaker items highlighted by the factor analysis. Whilst the cross-validation of the BARQ-C yielded a reasonable outcome the questionnaire most certainly could be improved, for example, through reformulation and/or addition of items from the UK Social support-seeking scale, Diffusion and Avoidance subscales in both Dutch and English. The BARQ-C should also be validated using existing sound instruments that measure anger coping styles.

\section{Limitations and Directions for Future Research}

A limitation of this study is that it employed self-report measures only, all of which came from the same informant. A result of this is that the chance of finding significant relationships is inflated. Self-report instruments are often criticized for not always reflecting true behavior as they are subject to response biases (e.g., Robinson and Clore 2002). A future study should aim to use different informants and/ or more objective measurements of these variables e.g., using a daily/weekly coping diary, to bolster the findings.

In terms of explaining somatic complaints this study was limited as it focused on the emotion anger. Quite a number of studies have already shown that both depression and anxiety are linked to somatic complaints (Campo et al. 2004; 1999; De Waal et al. 2004; Egger et al. 1999; Scharff 1997). An important future study would be to test the unique contribution of anger mood and anger coping styles, in the presence of these other important constructs. Indeed, if depression were measured and tested in this model the influence of rumination as a coping strategy for anger may be negated, given the overlap between these two constructs. 
To more accurately test the relationships between anger coping, anger mood and somatic complaints a longitudinal study is necessary, particularly to be able to establish causality. This study looks at just one possible pathway, that anger coping styles influence health outcomes through their impact on anger mood, which may describe how these constructs are linked together. However, it could be that the pathway is the other way around, such that the experience of pain results in higher levels of angry mood and particular coping styles which aim to reduce that emotion. Another possibility is the presence of reciprocal influences among the constructs anger coping, anger mood and physical complaints. It would be worthwhile for future research to compare the pathway here proposed with these alternatives using, for example, structural equation modeling.

A final point to mention is that although age was not found to mediate the relationships between anger coping and mood, nor contribute to somatic complaints, it was confounded with country. Because the Dutch sample was younger than the UK sample it was not possible to examine cross cultural differences and age effects simultaneously. Both variables should therefore be taken into account in future studies.

\section{Conclusions}

In conclusion, the present results suggest that it is important to take into account the role of the rather difficult emotion, anger, and how one manages it, when studying factors associated with physical health complaints among children and adolescents. In particular, dealing with anger in a way that merely serves the function of reworking the angering event either in one's own mind or with another person was found to independently contribute to British and Dutch participants' self-reported somatic complaints. This study also provides preliminary evidence to suggest that older children and adolescents, like adults, have a broader repertoire of anger coping strategies than just keeping feelings hidden, expressing them outwardly or holding them under control. In light of these findings it may be advantageous not only to approach depression and anxiety when treating frequent and persistent somatic complaints but also to consider how children and adolescents deal with their feelings of anger. If this age group are able to use a fairly wide range of strategies it might be possible to teach more positive coping styles that seek to resolve the angering event.

Acknowledgements The authors would like to thank Selina Chen, Joanna Penty, Jelle van der Poel, Abigail Tolland and Isa Wijk for their help collecting data for this study.

\section{References}

Achenbach, T. M., McConaughy, S. H., \& Howell, C. T. (1987). Child adolescent behavioral and emotional-problems-Implications of cross-informant correlations for situational specificity. Psychological Bulletin, 101, 213-232.

Averill, J. R. (1982). Anger and aggression: An essay on emotion. New York: Springer.

Baldwin, W. (2000). Information no one else knows: The value of self-report. In A. A. Stone, J. S. Turkkan, et al. (Eds.), The science of self-report: Implications for research and practice (pp. 3-7). Mahwah, NJ: Lawrence Erlbaum Associates.

Bandell-Hoekstra, I., Abu-Saad, H. H., Passchier, J., \& Knipschild, P. (2000). Recurrent headache, coping, and quality of life in children: A review. Headache, 40, 357-370.

Bonner, M. J., \& Finney, J. W. (1996). A psychosocial model of children's health status. In Advances in clinical child psychology, $18,231-282$

Bushman, B. J. (2002). Does venting anger feed or extinguish the flame? Catharsis, rumination, distraction, anger and aggressive responding. Personality and Social Psychology Bulletin, 28, 724-731.

Buss, K. A., \& Kiel, E. J. (2004). Comparison of sadness, anger, and fear facial expressions when toddlers look at their mothers. Children Development, 75, 1761-1773.

Campo, J. V., Bridge, J., Ehmann, M., Altman, S., Lucas, A., Birmaher, B., et al. (2004). Recurrent abdominal pain, anxiety, and depression in primary care. Pediatrics, 113, 817-824.

Campo, J. V., Jansen-McWilliams, L., Comer, D. M., \& Kelleher, K. J. (1999). Somatization in pediatric primary care: Association with psychopathology, functional impairment, and use of services. Journal of the American Academy of Child and Adolescent Psychiatry, 38, 1093-1101.

Compas, B. E., \& Harding Thomsen, A. (1999). Coping and responses to stress among children with recurrent abdominal pain. Developmental and Behavioral Pediatrics, 20, 323-324.

Connor-Smith, J. K., Compas, B. E., Wadsworth, M. E., Harding Thomsen, A., \& Saltzman, H. (2000). Responses to stress in adolescence: Measurement of coping and involuntary stress responses. Journal of Consulting and Clinical Psychology 68, 976-992.

Croffie, J. M., Fitzgerald, J. F., \& Chong, S. F. K. (2000). Recurrent abdominal pain in children-A retrospective study of outcome in a group referred to a pediatric gastroenterology practice. Clinical Pediatrics, 39, 267-274.

De Waal, M. W. H., Arnold, I. A., Eekhof, J. A. H., \& Van Hemert, A. M. (2004). Somatoform disorders in general practice - Prevalence, functional impairment and comorbidity with anxiety and depressive disorders. British Journal of Psychiatry, 184, 470-476.

DiBartolo, P. M., \& Grills, A. E. (2006). Who is best at predicting children's anxiety in response to a social evaluative task? A comparison of child, parent, and teacher reports. Journal of Anxiety Disorders, 20, 630-645.

DiGiuseppe, R., Eckhardt, C., Tafrate, R., \& Robin, M. (1994). The diagnosis and treatment of anger in a cross-cultural context. Journal of Social Distress and the Homeless, 3, 229-261.

Edwards, M. C., Mullins, L. L., Johnson, J., \& Bernardy, N. (1994). Survey of pediatricians' management practices for recurrent abdominal pain. Journal of Pediatric Psychology, 19, 241-253.

Egger, H. L., Costello, E. J., Erkanli, A., \& Angold, A. (1999). Somatic complaints and psychopathology in children and adolescents: Stomach aches, musculoskeletal pains, and headaches. Journal of the American Academy of Child and Adolescent Psychiatry, 38, 852-860

Eng, P. M., Fitzmaurice, G., Kubzansky, L. D., Rimm, E. B., \& Kawachi, I. (2003). Anger expression and risk of stroke and 
coronary heart disease among male health professionals. Psychosomatic Medicine, 65, 100-110.

Feldman-Barrett, L. (2004). The experience of emotion: Representation and the act of feeling. In First European CERE (Consortium of European Researchers on Emotion) Conference on Emotions. Amsterdam, The Netherlands.

Fernandez, E., \& Turk, D. C. (1995). The scope and significance of anger in the experience of chronic pain. Pain, 61, 165-175.

Fields, L., \& Prinz, R. J. (1997). Coping and adjustment during childhood and adolescence. Clinical Psychological Review, 17, 937-976.

Friedman, H. S., Tucker, J. S., \& Reise, S. P. (1995). Personality dimensions and measures potentially relevant to health: A focus on hostility. Annals of Behavioral Medicine, 17, 245-253.

Gallacher, J. E., Yarnell, J. W., Sweetnam, P. M., Elwood, P. C., \& Stansfeld, S. A. (1999). Anger and incident heart disease in the Caerphilly study. Psychosomatic Medicine, 61, 446-453.

Gentry, W. D., Chesney, A. P., Gary, H. G., Hall, R. P., \& Harburg, E. (1982). Habitual anger-coping styles. I. Effect on mean blood pressure and risk for essential hypertension. Psychosomatic Medicine, 44, 195-202.

Greenwood, K. A., Thurston, R., Rumble, M., Waters, S. J., \& Keefe, F. J. (2003). Anger and persistent pain: Current status and future directions. Pain, 103, 1-5.

Harburg, E., Gleiberman, L., Russell, M., \& Cooper, M. L. (1991). Anger coping styles and blood pressure in blacks and whites. Psychosomatic Medicine, 53, 153-164.

Hogan, B. E., \& Linden, W. (2004). Anger response styles and blood pressure: At least don't ruminate about it! Annals of Behavioral Medicine, 27, 38-49.

Jellesma, F. C., Rieffe, C., \& Meerum Terwogt, M. (in press). The Somatic Complaint List: Validation of a self-report questionnaire assessing somatic complaints in children. Journal of Psychosomatic Research.

Jellesma, F. C., Rieffe, C., Meerum Terwogt, M., \& Kneepkens, C. M. F. (2006). Somatic complaints and health care use in children: Mood, emotion awareness and sense of coherence. Social Science and Medicine, 63, 2640-2648.

Kerns, R., Rosenberg, R., \& Jacob, M. (1994). Anger expression and chronic pain. Journal of Behavioral Medicine, 17, 57-67.

Kuppens, P., Van Mechelen, I., \& Meulders, M. (2004). Every cloud has a silver lining: Interpersonal and individual differences determinants of anger-related behaviors. Personality and Social Psychology Bulletin, 30, 1550-1564.

Larsen, R. J., \& Prizmic, Z. (2006). Multimethod measurement of emotion. In M. Eid \& E. Diener (Eds.), Handbook of measurement: A multimethod perspective (pp. 337-352). Washington, DC: American Psychological Association.

Last, B. F., \& Grootenhuis, M. A. (1998). Emotions, coping and the need for support in families of children with cancer: A model for psychosocial care. Parent Education and Counselling, 33, 169-179.

Lemerise, E. A., \& Dodge, K. A. (1993). The development of anger and hostile interactions. In M. Lewis \& J. M. Haviland (Eds.), Handbook of emotions (pp. 537-546). New York: Guildford.

Linden, W., Hogan, B. E., Rutledge, T., Chawla, A., Lenz, J. W., \& Leung, D. (2003). There is more to anger coping than "in" or "out." Emotion, 3, 12-29.

Linden, W., Lenz, J. W., \& Con, A. H. (2001). Individualized stress management for primary hypertension: A randomized trial. Archives of Internal Medicine, 161, 1071-1080.

Losoya, S., Eisenberg, N., \& Fabes, R. A. (1998). Developmental issues in the study of coping. International Journal of Behavioral Development, 22, 287-313.

Markus, H. R., \& Kitayama, S. (1991). Culture and the selfImplications for cognition, emotion, and motivation. Psychological Review, 98, 224-253.
Martin, R., Wan, C. K., David, J. P., Wegner, E. L., Olson, B. D., \& Watson, D. (1999). Style of anger expression: Relation to expressivity, personality, and health. Personality and Social Psychology Bulletin, 25, 1196-1207.

Meerum Terwogt, M., Rieffe, C., Miers, A. C., Jellesma, F. C., \& Tolland, A. (2006). Emotions and self-esteem as indicators of somatic complaints in children. Infant and Child Development, $15,581-592$.

Mellor, D. (2004). Furthering the use of the strengths and difficulties questionnaire: Reliability with younger child respondents. Psychological Assessment, 16, 396-401.

Miller, T. Q., Jenkins, C. D., Kaplan, G. A., \& Salonen, J. T. (1995). Are all hostility scales alike? Factor structure and covariation among measures of hostility. Journal of Applied Social Psychology, 25, 1142-1168.

Moldofsky, H., \& Chester, W. (1970). Pain and mood patterns in patients with rheumatoid arthritis: A prospective study. Psychosomatic Medicine, 32, 309-318.

Nygaard, E. A., Stordal, K., \& Bentsen, B. S. (2004). Recurrent abdominal pain in children revisited: Irritable bowel syndrome and psychosomatic aspects. A prospective study. Scandinavian Journal Of Gastroenterology, 39, 938-940.

Pedhazur, E., \& Schmelkin, L. (1991). Measurement, design and analysis. Hillsdale, NJ: Erlbaum.

Perquin, C. W., Hazebroek-Kampschreur, A. A. J. M., Hunfeld, J. A. M., Bohnen, A. M., van Suijlekom-Smit, L. W. A., Passchier, J., et al. (2000a). Pain in children and adolescents: A common experience. Pain, 87, 51-58.

Perquin, C. W., Hazebroek-Kampschreur, A. A. J. M., Hunfeld, J. A. M., van Suijlekom-Smit, L. W. A., Passchier, J., \& van der Wouden, J. C. (2000b). Chronic pain among children and adolescents: Physician consultation and medication use. Clinical Journal of Pain, 16, 229-235.

Rector, N. A., \& Roger, D. (1996). Cognitive style and well-being: A prospective examination. Personality and Individual Differences, 21, 663-674.

Rieffe, C., \& Meerum Terwogt, M. (2006). Anger communication in deaf children. Cognition and Emotion, 20, 1261-1273.

Rieffe, C., Meerum Terwogt, M., \& Bosch, J. D. (2004). Emotion understanding in children with frequent somatic complaints. European Journal of Developmental Psychology, 1, 31-47.

Rieffe, C., Oosterveld, P., \& Meerum Terwogt, M. (2006). An alexithymia questionnaire for children: Factorial and concurrent validation results. Personality and Individual Differences, 40, $123-133$.

Riley, W. T., \& Treiber, F. A. (1989). The validity of multidimensional self-report anger and hostility measures. Journal of Clinical Psychology, 45, 397-404.

Robinson, M. D., \& Clore, G. L. (2002). Belief and feeling: Evidence for an accessibility model of emotional self-report. Psychological Bulletin, 128, 934-960.

Roth-Isigkeit, A., Thyen, U., Raspe, H. H., Stoven, H., \& Schmucker, P. (2004). Reports of pain among German children and adolescents: An epidemiological study. Acta Paediatrica, 93, 258-263.

Scharff, L. (1997). Recurrent abdominal pain in children: A review of psychological factors and treatment. Clinical Psychology Review, $17,145-166$.

Scherer, K. R. (2000). Emotion. In M. Hewstone \& W. Stroebe (Eds.), Introduction to social psychology: A European perspective, 3rd ed. (pp. 151-191). Oxford: Blackwell.

Sharrer, V. W., \& Ryan-Wenger, N. M. (1991). Measurements of stress and coping among school-aged children with and without recurrent abdominal pain. Journal of School Health, 61, 86-91.

Siegman, A. W., Anderson, R. A., Herbst, J., Boyle, S., \& Wilkinson, J. (1992). Dimensions of anger-hostility and cardiovascular 
reactivity in provoked and angered men. Journal of Behavioral Medicine, 15, 257-272.

Spielberger, C. D., Johnson, E. H., Russell, S. F., Crane, R. J., Jacobs, G. A., \& Worden, T. J. (1985). The experience and expression of anger: Construction and validation of an anger expression scale. In M. A. Chesney, R. H. Rosenman (Eds.), Anger and hostility in cardiovascular and behavioral disorders (pp. 5-30). New York: Hemisphere.

Suarez, E. C., \& Williams, R. B. (1990). The relationships between dimensions of hostility and cardiovascular reactivity as a function of task characteristics. Psychosomatic Medicine, 52, 558-570.

Tabachnick, B. G., \& Fidell, L. S. (2007). Using multivariate statistics, 5th ed. New York: Allyn \& Bacon.

Taylor, G. (1997). Introduction. In G. J. Taylor, R. M. Bagby, \& J. D. A. Parker (Eds.), Disorders of affect regulation (pp. 1-6). Cambridge: Cambridge University Press.

Taylor, D. C., Szatmari, P., Boyle, M. H., \& Offord, D. R. (1996). Somatization and the vocabulary of everyday bodily experiences and concerns: A community study of adolescents. Journal of the American Academy of Child and Adolescent Psychiatry, 35, 491-499.

Underwood, M. K. (1997). Peer social status and children's understanding of the expression and control of positive and negative emotions. Merrill-Palmer Quarterly, 43, 610-634.

Underwood, M. K., Coie, J. D., \& Herbsman, C. R. (1992). Display rules for anger and aggression in school-age children. Child Development, 63, 366-380. von Salisch, M., \& Vogelgesang, J. (2005). Anger regulation among friends: Assessment and development from childhood to adolescence. Journal of Social and Personal Relationships, 22, 837855.

Walker, L. S., \& Greene J. W. (1989). Children with recurrent abdominal pain and their parents: More somatic complaints, anxiety and depression than other patient families? Journal of Pediatric Psychology, 14, 231-243.

Walker, L. S., Garber, J., \& Greene, J. W. (1993). Psychosocial correlates of recurrent childhood pain-A comparison of pediatric-patients with recurrent abdominal-pain, organic illness, and psychiatric-disorders. Journal of Abnormal Psychology, 102, 248-258.

Walker, L. S., Garber, J., Smith, C. A., Van Slyke, D. A., \& Claar, R. L. (2001). The relation of daily stressors to somatic and emotional symptoms in children with and without recurrent abdominal pain. Journal of Consulting and Clinical Psychology, 69, 85-91.

Watkins, E. (2004). Appraisals and strategies associated with rumination and worry. Personality and Individual Differences, 37, 679-694.

Yarcheski, A., Mahon, N. E., \& Yarcheski, T. J. (2002). Anger in early adolescent boys and girls with health manifestations. Nursing Research, 51, 229-236.

Zimmerman, L., Story, K. T., Gaston-Johasson, F., \& Rowles, J. R. (1996). Psychological variables and cancer pain. Cancer Nursing, 19, 44-53. 